\title{
Design, Synthesis and Antitubercular Activity of 2-(Benzylthio)-1H-benzo[d]imidazoles
}

\author{
Raoní S. Rambo, ${ }^{\oplus a}$ Etienne C. Waldow, ${ }^{a}$ Bruno L. Abaddi, ${ }^{a}$ Maiele D. Silveira, ${ }^{a}$ \\ Adilio S. Dadda, ${ }^{a}$ Nathalia Sperotto, ${ }^{a}$ Cristiano V. Bizarro, ${ }^{a, b}$ Luiz Augusto Basso ${ }^{a, b, c}$ \\ and Pablo Machado ${ }^{\circledR *, a, b, c}$ \\ ${ }^{a}$ Instituto Nacional de Ciência e Tecnologia em Tuberculose, \\ Centro de Pesquisas em Biologia Molecular e Funcional, \\ Pontifícia Universidade Católica do Rio Grande do Sul, 90616-900 Porto Alegre-RS, Brazil \\ ${ }^{b}$ Programa de Pós-Graduação em Biologia Celular e Molecular, \\ Pontifícia Universidade Católica do Rio Grande do Sul, 90616-900 Porto Alegre-RS, Brazil \\ 'Programa de Pós-Graduação em Medicina e Ciências da Saúde, \\ Pontifícia Universidade Católica do Rio Grande do Sul, 90616-900 Porto Alegre-RS, Brazil
}

Using molecular simplification and molecular hybridization approaches, a series of 2-(benzylthio)-1 $H$-benzo[ $d]$ imidazoles was synthesized and evaluated as in vitro inhibitors of Mycobacterium tuberculosis (M. tuberculosis) growth. Compounds $\mathbf{6 p}$ and $\mathbf{6 z}$ were considered the lead compounds from this series of molecules, with minimal inhibitory concentration (MIC) values of 6.9 and $3.8 \mu \mathrm{M}$ against M. tuberculosis H37Rv, respectively. Additionally, the leading compounds were active against multidrug-resistant strains and were devoid of apparent toxicity to Vero and HepG2 cells, from 3-(4,5-dimethylthiazol-2-yl)-2,5-diphenyltetrazolium bromide (MTT) and neutral red assays. Finally, the compounds presented good aqueous solubility and high plasma stability. These data together indicate that this class of molecules may furnish new anti-tuberculosis drug candidates for future development. study

Keywords: Mycobacterium tuberculosis, tuberculosis, drug-resistant strain, preliminary SAR

\section{Introduction}

Tuberculosis (TB) is an airborne infectious disease caused mainly by Mycobacterium tuberculosis (Mtb). According to the World Health Organization (WHO), 10 million people have been affected by the disease, with an estimated 1.2 million deaths in 2019., ${ }^{1,2}$ The recommended treatment includes two months of isoniazid (INH), rifampicin (RIF), ethambutol (ETH) and pyrazinamide (PZA), followed by four more months of INH and RIF., ${ }^{3,4}$ Although it has a cure rate of up to $95 \%$, the regime suffers with an increasing number of individuals infected with drug-resistant strains. ${ }^{3}$ In these cases, the treatment can be extended and second-line drugs are needed, which are, in general, more expensive and toxic. ${ }^{4}$ Furthermore, the low adherence of patients to the regime treatment, adverse effects, toxicity events and difficulty of co-administration

*e-mail: pablo.machado@pucrs.br with some antiretroviral drugs have limited the use of this pharmacologic strategy. ${ }^{1}$

Within this context, new therapeutic alternatives are needed, if possible, acting via innovative mechanisms to overcome concerns of resistance to clinically available drugs. An example of this constant need for new anti-TB drugs is the reported emergence of Mtb-resistant strains against the recently approved drugs bedaquiline and delamanid. ${ }^{5}$

In an attempt to collaborate with the research of new drugs for TB treatment, our research group has developed strategies for obtaining drug candidates capable of inhibiting the growth of drug-susceptible and drug-resistant Mtb strains. ${ }^{6-8}$ Recently, a series of 2-quinoline-based compounds was synthesized. ${ }^{8}$ These compounds presented potent and selective activity against drug-susceptible and drug-resistant strains, with minimal inhibitory concentration (MIC) as low as $0.3 \mu \mathrm{M}(\mathbf{1}$, Figure 1). Our findings inferred that antitubercular activity elicited by 
synthesized molecules was carried out by targeting the cytochrome bc1 complex. Additionally, the compounds showed improved metabolic properties compared with their counterparts, and were able to inhibit intracellular Mtb growth. ${ }^{8}$ In another study, our research group demonstrated the antimycobacterial activity of 2-[(1H-benzo $[d]$ imidazol2-yl)thio]acetamide. ${ }^{9}$ The hybrids formed from the synthesis of acetamide-containing compounds provided structures with moderate activity. The top hit compound $\mathbf{2}$ (Figure 1) exhibited MIC value of $16.5 \mu \mathrm{M}$, opening up the possibility of new structural modifications aiming toward its optimization. It is noteworthy that 2-mercapto- $1 H$-benzo $[d]$ imidazole is also present as a scaffold of lansoprazole sulfide, the active metabolite from the lanzoprazole drug. Lansoprazole sulfide has presented significant activity against intracellular and in-broth cultures of Mtb, with half maximal inhibitory concentrations $\left(\mathrm{ICs}_{50}\right)$ of 0.59 and $0.46 \mu \mathrm{M}$, respectively. ${ }^{10}$ The structural requirements for the antimycobacterial activity of 2-quinolinebased compounds, along with the activity exhibited by $1 H$-benzo $[d]$ imidazole-containing molecules, prompted us to evaluate if the presence of benzyl substituents attached to a 5-methoxy-1H-benzo[ $d]$ imidazole (3) scaffold could provide new compounds with superior activity (Figure 1). It is important to point out that the methoxy group has been described as a pharmacophoric group of 2-quinoline-based structures. ${ }^{6,7}$

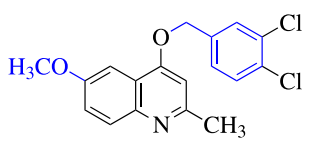

1 (INCT-TB765) $\mathrm{MIC}_{\mathrm{H} 37 \mathrm{Rv}}=0.3 \mu \mathrm{M}$

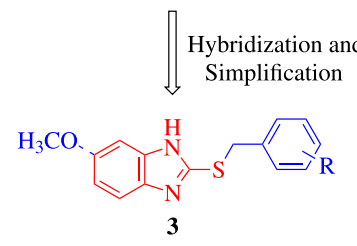

Figure 1. Design of new 2-(benzylthio)-1H-benzo[ $d]$ imidazoles $\mathbf{3}$, using molecular hybridization and molecular simplification approaches from 2-quinoline-based compound 1 (INCT-TB765) and 2-[(1H-benzo $[d]$ imidazol-2-yl)thio] acetamide 2 (INCT-TB808).

Therefore, in an attempt to obtain active compounds against drug-susceptible and, mainly, drug-resistant Mtb strains, a new series of 2-(benzylthio)-5-methoxy$1 H$-benzo[ $d]$ imidazoles was synthesized. The molecules were designed using classical molecular hybridization along with a molecular simplification approach. First, the preliminary structural requirements for potency of synthesized structures (structure activity relationship, SAR) were evaluated using MIC values. Subsequently, the most active structures against M. tuberculosis $\mathrm{H} 37 \mathrm{Rv}$ were tested against a panel of well-characterized multidrug-resistant strains, while the viability of HepG2 and Vero cells was used as an indicator of the toxicity and selectivity of the compounds.

\section{Experimental}

\section{Chemistry}

The progress of the reaction was monitored using thinlayer chromatography (TLC) with Silicycle TLC Silica gel 60 F254 (Quebec, Canada). The melting points were measured using a Microquímica MQAPF-302 apparatus (Palhoça, Brazil). ${ }^{1} \mathrm{H}$ and ${ }^{13} \mathrm{C}$ nuclear magnetic resonance (NMR) spectra were acquired on a Bruker Avance III HD spectrometer (Fällanden, Switzerland). Chemical shifts $(\delta)$ were expressed in parts per million ( $\mathrm{ppm}$ ) relative to dimethyl sulfoxide (DMSO- $d_{6}$ ), which was used as the solvent, and to tetramethylsilane (TMS), which was used as an internal standard. High-resolution mass spectra (HRMS) were obtained for all compounds on an LTQ Orbitrap Discovery mass spectrometer (Thermo Fisher Scientific, Bremen, Germany). The analyses were performed through the direct infusion of the sample in $\mathrm{MeOH} / \mathrm{MeCN}(1: 1)$ with $0.1 \%$ formic acid (flow rate $10 \mathrm{~mL} \mathrm{~min}^{-1}$ ), in a positive-ion or negative-ion mode using electrospray ionization (ESI). For elemental composition, calculations were performed using the specific tool included in the Qual Browser module of Xcalibur software (Thermo Fisher Scientific, Bremen, Germany). The compounds' purities, solubility assays and plasma stabilities were determined using a Dionex Ultimate 3000 UHPLC chromatograph (Germering, Germany). The liquid chromatography conditions were as follows: RP column, $5 \mathrm{~mm}$ Nucleodur C-18ec $(250 \times 4.6 \mathrm{~mm})$; flow rate, $1.5 \mathrm{~mL} \mathrm{~min}{ }^{-1}$; UV detection, $254 \mathrm{~nm} ; 100 \%$ water $(0.1 \%$ acetic acid) was maintained from 0 to $7 \mathrm{~min}$, followed by a linear gradient from $100 \%$ water $(0.1 \%$ acetic acid) to $90 \%$ acetonitrile/methanol $(1: 1, \mathrm{v} / \mathrm{v})$ from 7 to $15 \mathrm{~min}$ (15-30 $\mathrm{min})$, and subsequently returned to $100 \%$ water ( $0.1 \%$ acetic acid) in $5 \mathrm{~min}(30-35 \mathrm{~min})$ and maintained for an additional $10 \mathrm{~min}(35-45 \mathrm{~min})$. All the evaluated compounds were $\geq 90 \%$ pure. Commercially available reactants and solvents were obtained from commercial suppliers and were used without additional purification. Ethanol, chloroform, diethyl ether, hexane, ethyl acetate, hydrochloric acid, petroleum ether, and acetone were obtained from Química Moderna (Barueri, Brazil). Dimethylformamide (DMF), acetic acid (glacial), acetonitrile (high performance liquid chromatography (HPLC) grade), and methanol (HPLC grade) were obtained 
from Merck KGaA (Darmstadt, Germany). Potassium carbonate was purchased from Acros Organics B.V.B.A. (Geel, Belgium). Finally, resazurin, benzyl halides, imidazoles, DMSO (anhydrous), DMSO (for molecular biology), and DMSO- $d_{6}$ were obtained from Sigma-Aldrich Corporation (Saint Louis, USA). Additionally, $\mathrm{NaCl}, \mathrm{KCl}$, $\mathrm{Na}_{2} \mathrm{HPO}_{4}$, and $\mathrm{KH}_{2} \mathrm{PO}_{4}$ used for phosphate-buffered saline (PBS) preparation were also obtained from Sigma-Aldrich Corporation (Saint Louis, USA).

General procedure for the synthesis of compounds 6

To a round-bottom flask was added the respective imidazole $(0.5 \mathrm{mmol})$, the respective benzyl halide (1.2 equiv), potassium carbonate (1 equiv) and $\mathrm{DMF}(5 \mathrm{~mL})$. The mixture was stirred for 2-6 $\mathrm{h}$ until complete consumption of imidazole, followed by TLC. Then, the reaction was diluted in chloroform $(20 \mathrm{~mL})$ and washed with water $(3 \times 20 \mathrm{~mL})$. The organic layer was dried over sodium sulfate and the solvent evaporated under reduced pressure. The compounds were purified using column chromatography.

\section{2-(Benzylthio)-5-methoxy-1H-benzo[d]imidazole (6a)}

Purified by column chromatography eluting mixtures of hexanes and ethyl acetate ( $9: 1$ followed by $8: 2$ ) to obtain the title compound as a white solid in $67 \%$ yield; $\mathrm{mp} 126-129^{\circ} \mathrm{C}$; $\mathrm{t}_{\mathrm{R}} 15.2 \mathrm{~min} ;{ }^{1} \mathrm{H}$ NMR $\left(400 \mathrm{MHz}\right.$, DMSO- $\left.d_{6}\right) \delta 12.42(\mathrm{bs}, 1 \mathrm{H}$, $\mathrm{NH}), 7.49-7.18\left(\mathrm{~m}, 6 \mathrm{H}, 5 \mathrm{Ph}-\mathrm{H}\right.$ and $\left.1 \mathrm{Im}-\mathrm{H}^{*}\right), 6.97$ (bs, $1 \mathrm{H}, \mathrm{Im}-\mathrm{H}), 6.75$ (dd, 1H, J 8.7, 2.6 Hz, Im-H), 4.53 (d, 2H, $J 4.4 \mathrm{~Hz}, \mathrm{~S}-\mathrm{CH}_{2}$ ), 3.76 (d, $3 \mathrm{H}, J 1.4 \mathrm{~Hz}, \mathrm{O}-\mathrm{CH}_{3}$ ); HRMS (Fourier transform mass spectrometry (FTMS) + pESI) $m / z$, calcd. for $\mathrm{C}_{15} \mathrm{H}_{14} \mathrm{~N}_{2} \mathrm{~S}[\mathrm{M}+\mathrm{H}]^{+}: 271.0900$, found: 271.0887.*Im-H: imidazole hydrogens.

\section{2-((2-Fluorobenzyl)thio)-5-methoxy-1H-benzo[d]imidazole} (6b)

Purified by column chromatography eluting mixtures of hexanes and ethyl acetate ( $9: 1$ followed by 7:3) to obtain the title compound as a white solid in $80 \%$ yield; mp $94-97^{\circ} \mathrm{C}$; $\mathrm{t}_{\mathrm{R}} 15.5 \mathrm{~min} ;{ }^{1} \mathrm{H}$ NMR (400 MHz, DMSO- $d_{6}$ ) $\delta 12.48$ (bs, $1 \mathrm{H}, \mathrm{NH}), 7.46$ (dd, 2H, J 26.9, 7.9 Hz, Ph-H), 7.34-7.15 (m, 2H, $1 \mathrm{Ph}-\mathrm{H}$ and $1 \mathrm{Im}-\mathrm{H}), 7.10(\mathrm{~d}, 1 \mathrm{H}, J 7.3 \mathrm{~Hz}, \mathrm{Ph}-\mathrm{H})$, $6.88(\mathrm{~s}, 1 \mathrm{H}, \mathrm{Im}-\mathrm{H}), 6.76(\mathrm{~d}, 1 \mathrm{H}, J 8.8 \mathrm{~Hz}, \mathrm{Im}-\mathrm{H}), 4.54$ (d, $2 \mathrm{H}, J 7.6 \mathrm{~Hz}, \mathrm{~S}-\mathrm{CH}_{2}$ ), 3.76 (s, 3H, O- $\mathrm{CH}_{3}$ ); HRMS (FTMS + pESI) $m / z$, calcd. for $\mathrm{C}_{15} \mathrm{H}_{13} \mathrm{FN}_{2} \mathrm{~S}[\mathrm{M}+\mathrm{H}]^{+}$: 289.0805, found: 289.0790 .

\section{2-((3-Fluorobenzyl)thio)-5-methoxy-1H-benzo[d]imidazole} (6c)

Purified by column chromatography eluting mixtures of hexanes and ethyl acetate $(9: 1$ followed by $7: 3)$ to obtain the title compound as a light yellow solid in 66\% yield; mp 94- $97{ }^{\circ} \mathrm{C} ; \mathrm{t}_{\mathrm{R}} 15.7 \mathrm{~min} ;{ }^{1} \mathrm{H}$ NMR (400 MHz, DMSO- $d_{6}$ ) $\delta 12.44$ (bs, $1 \mathrm{H}, \mathrm{NH}), 7.41-7.22(\mathrm{~m}, 4 \mathrm{H}, 3 \mathrm{Ph}-\mathrm{H}$ and $1 \mathrm{Im}-\mathrm{H}), 7.07$ (ddd, 1H, J 10.3, 8.3, $2.7 \mathrm{~Hz}, \mathrm{Ph}-\mathrm{H}), 6.97$ (bs, 1H, Im-H), 6.75 (dd, 1H, J 8.7, 2.4 Hz, Im-H), 4.53 (s, $\left.2 \mathrm{H}, \mathrm{S}-\mathrm{CH}_{2}\right), 3.76\left(\mathrm{~s}, 3 \mathrm{H}, \mathrm{O}-\mathrm{CH}_{3}\right) ; \mathrm{HRMS}(\mathrm{FTMS}+\mathrm{pESI})$ $\mathrm{m} / z$, calcd. for $\mathrm{C}_{15} \mathrm{H}_{13} \mathrm{FN}_{2} \mathrm{~S}[\mathrm{M}+\mathrm{H}]^{+}: 289.0805$, found: 289.0790 .

2-((4-Fluorobenzyl)thio)-5-methoxy-1H-benzo[d]imidazole (6d)

Purified by column chromatography eluting mixtures of hexanes and ethyl acetate (9:1 followed by $8: 2$ ) to obtain the title compound as a white solid in $70 \%$ yield; mp 133-135 ${ }^{\circ} \mathrm{C} ; \mathrm{t}_{\mathrm{R}} 15.5 \mathrm{~min} ;{ }^{1} \mathrm{H}$ NMR (400 MHz, DMSO- $d_{6}$ ) $\delta 12.44$ (bs, $\left.1 \mathrm{H}, \mathrm{NH}\right), 7.51-7.37$ (m, 3H, $2 \mathrm{Ph}-\mathrm{H}$ and $1 \mathrm{Im}-\mathrm{H}), 7.16-7.06(\mathrm{~m}, 2 \mathrm{H}, \mathrm{Ph}-\mathrm{H}), 6.88(\mathrm{bs}, 1 \mathrm{H}, \mathrm{Im}-\mathrm{H})$, 6.75 (dd, 1H, J 8.7, 2.4 Hz, Im-H), 4.51 (s, $\left.2 \mathrm{H}, \mathrm{S}_{-} \mathrm{CH}_{2}\right)$, 3.75 (s, 3H, O-CH CH $_{3}$; HRMS (FTMS + pESI) $\mathrm{m} / \mathrm{z}$, calcd. for $\mathrm{C}_{15} \mathrm{H}_{13} \mathrm{FN}_{2} \mathrm{~S}[\mathrm{M}+\mathrm{H}]^{+}:$289.0805, found: 289.0790 .

\section{2-((3,4-Difluorobenzyl)thio)-5-methoxy-1H-benzo[d] imidazole (6e)}

Purified by column chromatography eluting mixtures of hexanes and ethyl acetate $(9: 1$ followed by $7: 3)$ to obtain the title compound as a white solid in $70 \%$ yield; mp 136-139 ${ }^{\circ} \mathrm{C} ; \mathrm{t}_{\mathrm{R}} 16.1 \mathrm{~min} ;{ }^{1} \mathrm{HNMR}$ (400 MHz, DMSO- $d_{6}$ ) $\delta 12.45$ (bs, $1 \mathrm{H}, \mathrm{NH}), 7.54-7.44$ (m, 1H, Im-H), 7.42-7.20 (m, 3H, Ph-H), 6.98 (bs, 1H, Im-H), 6.75 (dd, 1H, J 8.7, $2.4 \mathrm{~Hz}, \mathrm{Im}-\mathrm{H}), 4.50$ (s, 2H, S-CH $), 3.75$ (s, 3H, O- $\mathrm{CH}_{3}$ ); HRMS (FTMS + pESI) $\mathrm{m} / z$, calcd. for $\mathrm{C}_{15} \mathrm{H}_{12} \mathrm{~F}_{2} \mathrm{~N}_{2} \mathrm{OS}$ $[\mathrm{M}+\mathrm{H}]^{+}:$307.0711, found: 307.0694 .

\section{2-((2-Chlorobenzyl)thio)-5-methoxy-1H-benzo[d]imidazole} (6f)

Purified by column chromatography eluting mixtures of hexanes and ethyl acetate (9:1 followed by 8:2) to obtain the title compound as a yellow oil in $90 \%$ yield; $t_{R} 16.3 \mathrm{~min}$; ${ }^{1} \mathrm{H}$ NMR (400 MHz, DMSO- $d_{6}$ ) $\delta 12.62(\mathrm{bs}, 1 \mathrm{H}, \mathrm{NH})$, 7.62-7.53 (m, 1H, Im-H), 7.48 (td, $1 \mathrm{H}, J 10.7,9.2,4.5 \mathrm{~Hz}$, Ph-H), 7.36-7.22 (m, 3H, Ph-H), 6.98-6.86 (m, 1H, Im-H), 6.76 (dd, 1H, J 8.7, 2.4 Hz, Im-H), 4.61 (s, $2 \mathrm{H}, \mathrm{S}_{-} \mathrm{CH}_{2}$ ), 3.77 (s, 3H, O-CH $_{3}$; HRMS (FTMS + pESI) $\mathrm{m} / z$, calcd. for $\mathrm{C}_{15} \mathrm{H}_{13} \mathrm{ClN}_{2} \mathrm{OS}[\mathrm{M}+\mathrm{H}]^{+}:$305.0510, found: 305.0493 .

\section{2-((3-Chlorobenzyl)thio)-5-methoxy-1H-benzo[d]imidazole} $(6 \mathrm{~g})$

Purified by column chromatography eluting mixtures of hexanes and ethyl acetate (9:1 followed by $8: 2$ ) to obtain the title compound as a white solid in $74 \%$ yield; mp 132-135 ${ }^{\circ} \mathrm{C}$; $\mathrm{t}_{\mathrm{R}} 16.4 \mathrm{~min} ;{ }^{1} \mathrm{H}$ NMR (400 MHz, 
DMSO- $\left.d_{6}\right) \delta 12.46(\mathrm{bs}, 1 \mathrm{H}, \mathrm{NH}), 7.51(\mathrm{~d}, 1 \mathrm{H}, J 2.1 \mathrm{~Hz}$, Im-H), 7.42-7.24 (m, 4H, Ph-H), 6.96 (bs, 1H, Im-H), 6.75 (dd, 1H, J 8.7, $2.5 \mathrm{~Hz}, \mathrm{Im}-\mathrm{H}), 4.52$ (s, 2H, S-CH ${ }_{2}$, 3.75 (s, 3H, O-CH ${ }_{3}$; HRMS (FTMS + pESI) $\mathrm{m} / z$, calcd. for $\mathrm{C}_{15} \mathrm{H}_{13} \mathrm{ClN}_{2} \mathrm{OS}[\mathrm{M}+\mathrm{H}]^{+}:$305.0510, found: 305.0494 .

\section{2-((4-Chlorobenzyl)thio)-5-methoxy-1H-benzo[d]imidazole} $(6 h)^{11}$

Purified by column chromatography eluting mixtures of hexanes and ethyl acetate (8:2 followed by $7: 3$ ) to obtain the title compound as a white solid in $95 \%$ yield; mp 131-134 ${ }^{\circ} \mathrm{C}$; $\mathrm{t}_{\mathrm{R}} 16.3 \mathrm{~min} ;{ }^{1} \mathrm{H}$ NMR $(400 \mathrm{MHz}$, DMSO- $\left.d_{6}\right) \delta 12.44$ (bs, $\left.1 \mathrm{H}, \mathrm{NH}\right), 7.48-7.41$ (m, 2H, $1 \mathrm{Im}-\mathrm{H}$ and $1 \mathrm{Ph}-\mathrm{H}), 7.38-7.30(\mathrm{~m}, 3 \mathrm{H}, \mathrm{Ph}-\mathrm{H}), 6.95$ (bs, $1 \mathrm{H}, \mathrm{Im}-\mathrm{H})$, 6.75 (dd, 1H, J 8.7, $2.4 \mathrm{~Hz}, \mathrm{Im}-\mathrm{H}), 4.52\left(\mathrm{~s}, 2 \mathrm{H}, \mathrm{S}_{-} \mathrm{CH}_{2}\right)$, $3.76\left(\mathrm{~s}, 3 \mathrm{H}, \mathrm{O}-\mathrm{CH}_{3}\right)$; HRMS (FTMS + pESI) $\mathrm{m} / z$, calcd. for $\mathrm{C}_{15} \mathrm{H}_{13} \mathrm{ClN}_{2} \mathrm{OS}[\mathrm{M}+\mathrm{H}]^{+}: 305.0510$, found: 305.0491 .

2-((3,4-Dichlorobenzyl)thio)-5-methoxy-1H-benzo[d] imidazole (6i)

Purified by column chromatography eluting mixtures of hexanes and ethyl acetate (8:2 followed by $7: 3$ ) to obtain the title compound as a white solid in $72 \%$ yield; mp 140-143 ${ }^{\circ} \mathrm{C}$; $\mathrm{t}_{\mathrm{R}} 17.2 \mathrm{~min} ;{ }^{1} \mathrm{H}$ NMR $(400 \mathrm{MHz}$, DMSO- $\left.d_{6}\right) \delta 12.43(\mathrm{bs}, 1 \mathrm{H}, \mathrm{NH}), 7.71(\mathrm{~d}, 1 \mathrm{H}, J 2.0 \mathrm{~Hz}$, $\mathrm{Ph}-\mathrm{H}), 7.54$ (d, 1H, $J 8.2 \mathrm{~Hz}, \mathrm{Im}-\mathrm{H}), 7.41$ (dd, $1 \mathrm{H}, J$ 8.3, $2.1 \mathrm{~Hz}, \mathrm{Ph}-\mathrm{H}$ ), 7.35 (bs, 1H, Ph-H), 6.97 (bs, 1H, Im-H), 6.75 (dd, 1H, J 8.7, $2.4 \mathrm{~Hz}, \mathrm{Im}-\mathrm{H}), 4.51$ (s, 2H, S-CH ${ }_{2}$, $3.76\left(\mathrm{~s}, 3 \mathrm{H}, \mathrm{O}-\mathrm{CH}_{3}\right)$; HRMS (FTMS + pESI) $\mathrm{m} / z$, calcd. for $\mathrm{C}_{15} \mathrm{H}_{13} \mathrm{Cl}_{2} \mathrm{~N}_{2} \mathrm{OS}[\mathrm{M}+\mathrm{H}]^{+}: 339.0120$, found: 339.0101 .

\section{2-((4-Bromobenzyl)thio)-5-methoxy-1H-benzo[d]imidazole} $(6 \mathbf{j})^{11}$

Purified by column chromatography eluting mixtures of hexanes and ethyl acetate (8:2 followed by $7: 3$ ) to obtain the title compound as a white solid in $68 \%$ yield; mp $128-131{ }^{\circ} \mathrm{C}$; $\mathrm{t}_{\mathrm{R}} 16.6 \mathrm{~min} ;{ }^{1} \mathrm{H}$ NMR $(400 \mathrm{MHz}$, DMSO- $\left.d_{6}\right) \delta 12.33(\mathrm{bs}, 1 \mathrm{H}, \mathrm{NH}), 7.49$ (dt, $J 8.0,1.5 \mathrm{~Hz}$, $2 \mathrm{H}, \mathrm{Ph}-\mathrm{H}$ ), 7.42-7.30 (m, 3H, $2 \mathrm{Ph}-\mathrm{H}$ and $1 \mathrm{Im}-\mathrm{H}), 6.97$ $(\mathrm{s}, 1 \mathrm{H}, \mathrm{Im}-\mathrm{H}), 6.75(\mathrm{dt}, 1 \mathrm{H}, J 8.7,1.6 \mathrm{~Hz}, \mathrm{Im}-\mathrm{H}), 4.50(\mathrm{~s}$, $\left.2 \mathrm{H}, \mathrm{S}-\mathrm{CH}_{2}\right), 3.76\left(\mathrm{~s}, 3 \mathrm{H}, \mathrm{O}-\mathrm{CH}_{3}\right) ; \mathrm{HRMS}(\mathrm{FTMS}+\mathrm{pESI})$ $m / z$, calcd. for $\mathrm{C}_{15} \mathrm{H}_{13} \mathrm{BrN}_{2} \mathrm{OS}[\mathrm{M}+\mathrm{H}]^{+}: 349.0005$, found: 348.9984 .

\section{2-((3-(Trifluoromethyl)benzyl)thio)-5-methoxy-1H-benzo[d]} imidazole (6k)

Purified by column chromatography eluting mixtures of hexanes and ethyl acetate (8:2 followed by $7: 3$ ) to obtain the title compound as a white solid in $78 \%$ yield; mp $122-125{ }^{\circ} \mathrm{C}$; $\mathrm{t}_{\mathrm{R}} 16.6 \mathrm{~min} ;{ }^{1} \mathrm{H}$ NMR $(400 \mathrm{MHz}$, DMSO- $\left.d_{6}\right) \delta 12.37$ (s, $\left.1 \mathrm{H}, \mathrm{NH}\right), 7.83(\mathrm{~s}, 1 \mathrm{H}, \mathrm{Ph}-\mathrm{H}), 7.74$ (d, 1H, J 7.7 Hz, Ph-H), 7.59 (d, 1H, J 7.9 Hz, Ph-H), 7.52 (t, 1H, J 7.5 Hz, Im-H), 7.34 (d, 1H, J 8.7 Hz, Ph-H), 6.97 (bs, 1H, Im-H), 6.75 (dt, 1H, J 8.7, $2.1 \mathrm{~Hz}, \mathrm{Im}-\mathrm{H}), 4.61$ (d, $\left.2 \mathrm{H}, J 1.8 \mathrm{~Hz}, \mathrm{~S}-\mathrm{CH}_{2}\right), 3.76\left(\mathrm{~d}, 3 \mathrm{H}, J 1.5 \mathrm{~Hz}, \mathrm{O}-\mathrm{CH}_{3}\right) ; \mathrm{HRMS}$ $\left(\right.$ FTMS + pESI) $m / z$, calcd. for $\mathrm{C}_{16} \mathrm{H}_{13} \mathrm{~F}_{3} \mathrm{~N}_{2} \mathrm{OS}[\mathrm{M}+\mathrm{H}]^{+}$: 339.0773, found: 339.0753 .

\section{2-((4-(Trifluoromethyl)benzyl)thio)-5-methoxy-1H-benzo[d] imidazole (6I)}

Purified by column chromatography eluting mixtures of hexanes and ethyl acetate (8:2 followed by $7: 3$ ) to obtain the title compound as a white solid in $76 \%$ yield; mp 163-165 ${ }^{\circ} \mathrm{C}$; $\mathrm{t}_{\mathrm{R}} 16.7 \mathrm{~min} ;{ }^{1} \mathrm{H}$ NMR $(400 \mathrm{MHz}$, DMSO- $\left.d_{6}\right) \delta 12.35$ (bs, $\left.1 \mathrm{H}, \mathrm{NH}\right), 7.67-7.61$ (m, $3 \mathrm{Ph}-\mathrm{H}$ and $1 \mathrm{Im}-\mathrm{H}), 7.34$ (d, 1H, J $8.8 \mathrm{~Hz}, \mathrm{Ph}-\mathrm{H}), 6.97$ (s, 1H, Im-H), 6.75 (ddt, $1 \mathrm{H}, J 8.8,2.7,1.6 \mathrm{~Hz}, \mathrm{Im}-\mathrm{H}), 4.61$ (s, $2 \mathrm{H}, \mathrm{S}_{-} \mathrm{CH}_{2}$ ), 3.76 (s, 3H, O-CH ${ }_{3}$; HRMS (FTMS + pESI) $\mathrm{m} / z$, calcd. for $\mathrm{C}_{16} \mathrm{H}_{13} \mathrm{~F}_{3} \mathrm{~N}_{2} \mathrm{OS}[\mathrm{M}+\mathrm{H}]^{+}:$339.0773, found: 339.0753 .

\section{2-((2-Nitrobenzyl)thio)-5-methoxy-1H-benzo[d]imidazole} $(6 \mathrm{~m})$

Purified by column chromatography eluting mixtures of hexanes and ethyl acetate ( $8: 2$ followed by $7: 3$ ) to obtain the title compound as a yellow oil in $82 \%$ yield; $t_{\mathrm{R}} 15.9 \mathrm{~min}$; ${ }^{1} \mathrm{H}$ NMR (400 MHz, DMSO- $d_{6}$ ) $\delta 12.33$ (bs, $\left.1 \mathrm{H}, \mathrm{NH}\right), 8.03$ (dt, $1 \mathrm{H}, J$ 8.2, $1.2 \mathrm{~Hz}, \mathrm{Ph}-\mathrm{H}), 7.74$ (dd, $1 \mathrm{H}, J 7.6,1.4 \mathrm{~Hz}$, $\mathrm{Ph}-\mathrm{H}), 7.66$ (td, 1H, J 7.5, $1.3 \mathrm{~Hz}, \mathrm{Ph}-\mathrm{H}), 7.52$ (td, 1H, $J$ 7.8, 7.3, $1.4 \mathrm{~Hz}, \mathrm{Im}-\mathrm{H}), 7.33$ (d, 1H, J 8.2 Hz, Ph-H), 6.95 (bs, $1 \mathrm{H}, \mathrm{Im}-\mathrm{H}), 6.74$ (ddd, $1 \mathrm{H}, J 8.7,2.5,1.1 \mathrm{~Hz}$, Im-H), 4.81 (s, 2H, S-CH $), 3.76$ (s, 3H, O-CH CH $_{3}$ HRMS (FTMS + pESI) $m / z$, calcd. for $\mathrm{C}_{15} \mathrm{H}_{13} \mathrm{~N}_{3} \mathrm{O}_{3} \mathrm{~S}[\mathrm{M}+\mathrm{H}]^{+}$: 316.0750, found: 316.0734 .

\section{2-((3-Nitrobenzyl)thio)-5-methoxy-1H-benzo[d]imidazole} (6n)

Reaction performed at $40{ }^{\circ} \mathrm{C}$ for $4 \mathrm{~h}$. After, the crude mixture was purified by column chromatography eluting mixture of petroleum ether and acetone (8:2) to obtain the title compound as a white solid in $66 \%$ yield; $\mathrm{mp} 172-175^{\circ} \mathrm{C}$; $\mathrm{t}_{\mathrm{R}} 15.8 \mathrm{~min} ;{ }^{1} \mathrm{H}$ NMR (400 MHz, DMSO- $\left.d_{6}\right) \delta 8.38(\mathrm{~d}, 1 \mathrm{H}$, $J ~ 2.1 \mathrm{~Hz}, \mathrm{Ph}-\mathrm{H}), 8.13-8.07(\mathrm{~m}, 1 \mathrm{H}, \mathrm{Ph}-\mathrm{H}), 7.94(\mathrm{dt}, 1 \mathrm{H}$, $J$ 7.7, 1.4 Hz, Ph-H), 7.60 (t, 1H, J 8.0 Hz, Ph-H), 7.54 (d, $1 \mathrm{H}, J 8.9 \mathrm{~Hz}, \mathrm{Im}-\mathrm{H}), 7.10(\mathrm{~d}, 1 \mathrm{H}, J 2.4 \mathrm{~Hz}, \mathrm{Im}-\mathrm{H}), 7.01(\mathrm{dd}$, $1 \mathrm{H}, J$ 8.9, $2.4 \mathrm{~Hz}, \mathrm{Im}-\mathrm{H}), 4.96$ (s, 2H, S-CH $\left.{ }_{2}\right), 3.81$ (s, 3H, $\mathrm{O}-\mathrm{CH}_{3}$ ); HRMS (FTMS + pESI) $\mathrm{m} / z$, calcd. for $\mathrm{C}_{15} \mathrm{H}_{13} \mathrm{~N}_{3} \mathrm{O}_{3} \mathrm{~S}$ $[\mathrm{M}+\mathrm{H}]^{+}:$316.0750, found: 316.0728 .

2-((4-Nitrobenzyl)thio)-5-methoxy-1H-benzo[d]imidazole (6o)

Purified by column chromatography eluting mixtures of hexanes and diethyl ether (1:1 followed by $3: 7)$ to 
obtain the title compound as a yellow solid in $75 \%$ yield; $\mathrm{mp} 170-172{ }^{\circ} \mathrm{C} ; \mathrm{t}_{\mathrm{R}} 15.9 \mathrm{~min} ;{ }^{1} \mathrm{H} \mathrm{NMR}\left(400 \mathrm{MHz}\right.$, DMSO- $\left.d_{6}\right)$ $\delta 12.42$ (bs, 1H, NH), 8.18-8.13 (m, 2H, Ph-H), 7.73-7.67 (m, 2H, $1 \mathrm{Ph}-\mathrm{H}$ and $1 \mathrm{Im}-\mathrm{H}), 7.34$ (d, 1H, J $8.4 \mathrm{~Hz}, \mathrm{Ph}-\mathrm{H})$, 7.00-6.92 (m, 1H, Im-H), $6.75(\mathrm{dd}, 1 \mathrm{H}, J$ 8.7, $2.4 \mathrm{~Hz}$, $\mathrm{Im}-\mathrm{H}$ ), 4.65 (s, 2H, S-CH $), 3.75$ (s, 3H, O-CH $\mathrm{CH}_{3}$; HRMS (FTMS + pESI) $m / z$, calcd. for $\mathrm{C}_{15} \mathrm{H}_{13} \mathrm{~N}_{3} \mathrm{O}_{3} \mathrm{~S}[\mathrm{M}+\mathrm{H}]^{+}$: 316.0750, found: 316.0733 .

\section{2-((3,5-Dinitrobenzyl)thio)-5-methoxy-1H-benzo[d]imidazole} (6p)

Purified by column chromatography eluting mixtures of hexanes and ethyl acetate (8:2 followed by $7: 3)$ to obtain the title compound as a yellow solid in $72 \%$ yield; mp $159-162{ }^{\circ} \mathrm{C} ; \mathrm{t}_{\mathrm{R}} 16.4 \mathrm{~min} ;{ }^{1} \mathrm{H} \mathrm{NMR}\left(400 \mathrm{MHz}\right.$, DMSO- $\left.d_{6}\right)$ $\delta 12.51(\mathrm{bs}, 1 \mathrm{H}, \mathrm{NH}), 8.83-8.76(\mathrm{~m}, 2 \mathrm{H}, \mathrm{Ph}-\mathrm{H}), 8.66(\mathrm{~d}, 1 \mathrm{H}$, $J 2.2 \mathrm{~Hz}, \mathrm{Ph}-\mathrm{H}$ ), 7.33 (bs, 1H, Im-H), 6.94 (bs, 1H, Im-H), $6.73(\mathrm{dd}, 1 \mathrm{H}, J$ 8.8, $2.4 \mathrm{~Hz}, \mathrm{Im}-\mathrm{H}), 4.75$ (s, 2H, S-CH $)$, 3.74 (s, 3H, O-CH C $_{3}$; HRMS (FTMS + pESI) $\mathrm{m} / 2$, calcd. for $\mathrm{C}_{15} \mathrm{H}_{12} \mathrm{~N}_{4} \mathrm{O}_{5} \mathrm{~S}[\mathrm{M}+\mathrm{H}]^{+}: 361.0601$, found: 361.0582 .

\section{2-((4-Isopropylbenzyl)thio)-5-methoxy- $1 H$-benzo[d] imidazole $(\mathbf{6 q})^{11}$}

Purified by column chromatography eluting mixtures of hexanes and ethyl acetate (9:1 followed by $8: 2$ ) to obtain the title compound as a white solid in $81 \%$ yield; mp 147-150 ${ }^{\circ} \mathrm{C}$; $\mathrm{t}_{\mathrm{R}} 17.0 \mathrm{~min} ;{ }^{1} \mathrm{H}$ NMR $(400 \mathrm{MHz}$, DMSO- $\left.d_{6}\right) \delta 12.37$ (bs, $\left.1 \mathrm{H}, \mathrm{NH}\right), 7.36-7.31(\mathrm{~m}, 3 \mathrm{H}, 1$ $\mathrm{Im}-\mathrm{H}$ and $2 \mathrm{Ph}-\mathrm{H}), 7.16(\mathrm{dt}, 2 \mathrm{H}, J$ 8.0, $2.1 \mathrm{~Hz}, \mathrm{Ph}-\mathrm{H}), 6.97$ (bs, 1H, Im-H), 6.75 (dt, 1H, J 8.7, $2.4 \mathrm{~Hz}, \mathrm{Im}-\mathrm{H}), 4.49$ (d, $\left.2 \mathrm{H}, J 2.5 \mathrm{~Hz}, \mathrm{~S}-\mathrm{CH}_{2}\right), 3.76\left(\mathrm{~d}, J 2.5 \mathrm{~Hz}, 3 \mathrm{H}, \mathrm{O}-\mathrm{CH}_{3}\right)$, $2.50(\mathrm{q}, 1 \mathrm{H}, J 1.8 \mathrm{~Hz}, \mathrm{CH}), 1.16(\mathrm{dt}, 6 \mathrm{H}, J 7.1,1.9 \mathrm{~Hz}$, $2 \mathrm{CH}_{3}$ ); HRMS (FTMS + pESI) $\mathrm{m} / z$, calcd. for $\mathrm{C}_{18} \mathrm{H}_{20} \mathrm{~N}_{2} \mathrm{OS}$ $[\mathrm{M}+\mathrm{H}]^{+}:$313.1369, found: 313.1350 .

\section{2-(4-tert-Butylbenzyl)-5-methoxy-1H-benzo[d]imidazole $(6 r)^{11}$}

Purified by column chromatography eluting mixtures of hexanes and ethyl acetate (9:1 followed by $8: 2$ ) to obtain the title compound as a white solid in $78 \%$ yield; mp 201-204 ${ }^{\circ} \mathrm{C}$; $\mathrm{t}_{\mathrm{R}} 17.3 \mathrm{~min} ;{ }^{1} \mathrm{H}$ NMR $(400 \mathrm{MHz}$, DMSO- $\left.d_{6}\right) \delta 12.35(\mathrm{~s}, 1 \mathrm{H}, \mathrm{NH}), 7.37-7.29(\mathrm{~m}, 5 \mathrm{H}, 4 \mathrm{Ph}-\mathrm{H}$ and $1 \mathrm{Im}-\mathrm{H}), 6.97(\mathrm{~s}, 1 \mathrm{H}, \mathrm{Im}-\mathrm{H}), 6.75(\mathrm{dd}, 1 \mathrm{H}, J$ 8.7, $2.4 \mathrm{~Hz}, \mathrm{Im}-\mathrm{H}$ ), 4.49 (s, 2H, S-CH ${ }_{2}$ ), 3.76 (s, 3H, O- $\mathrm{CH}_{3}$ ), $1.24\left(\mathrm{~s}, 9 \mathrm{H}, 3 \mathrm{CH}_{3}\right)$; HRMS (FTMS + pESI) $\mathrm{m} / z$, calcd. for $\mathrm{C}_{15} \mathrm{H}_{12} \mathrm{~N}_{4} \mathrm{O}_{5} \mathrm{~S}[\mathrm{M}+\mathrm{H}]^{+}:$327.1526, found: 327.1506 .

\section{5-Methoxy-2-((4-(methylsulfonyl)benzyl)thio)-1H-benzo[d] imidazole (6s)}

Purified by column chromatography eluting mixtures of hexanes and ethyl acetate $(7: 3$ followed by $1: 1)$ to obtain the title compound as a white solid in $83 \%$ yield; mp 137-140 ${ }^{\circ} \mathrm{C}$; $\mathrm{t}_{\mathrm{R}} 14.3 \mathrm{~min} ;{ }^{1} \mathrm{H}$ NMR (400 MHz, DMSO- $\left.d_{6}\right) \delta 12.43$ (bs, $\left.1 \mathrm{H}, \mathrm{NH}\right), 7.89-7.82(\mathrm{~m}, 2 \mathrm{H}, \mathrm{Ph}-\mathrm{H})$, 7.70 (d, 2H, J 8.1 Hz, Ph-H), 7.34 (d, 1H, J 8.8 Hz, Im-H), 6.97 (s, 1H, Im-H), 6.75 (dd, 1H, J 8.7, 2.4 Hz, Im-H), 4.63 (s, $\left.2 \mathrm{H}, \mathrm{S}-\mathrm{CH}_{2}\right), 3.76$ (s, $\left.3 \mathrm{H}, \mathrm{O}-\mathrm{CH}_{3}\right), 3.18\left(\mathrm{~s}, 3 \mathrm{H}, \mathrm{SO}_{2}-\mathrm{CH}_{3}\right)$; HRMS (FTMS + pESI) $\mathrm{m} / z$, calcd. for $\mathrm{C}_{16} \mathrm{H}_{16} \mathrm{~N}_{2} \mathrm{O}_{3} \mathrm{~S}_{2}$ $[\mathrm{M}+\mathrm{H}]^{+}:$349.0675, found: 349.0657 .

\section{2-((3,4-Difluorobenzyl)thio)-1H-benzo[d]imidazole (6t)}

Purified by column chromatography eluting mixtures of hexanes and ethyl acetate $(9: 1$ followed by $8: 2)$ to obtain the title compound as a brown solid in $22 \%$ yield; mp 108-110 ${ }^{\circ} \mathrm{C}$ (lit. 127-130 ${ }^{\circ} \mathrm{C}$ ) $;^{12} \mathrm{t}_{\mathrm{R}} 16.3 \mathrm{~min}$; ${ }^{1} \mathrm{H}$ NMR (400 MHz, DMSO- $\left.d_{6}\right) \delta 12.60(\mathrm{bs}, 1 \mathrm{H}, \mathrm{NH})$, 7.53 (ddd, 1H, J 11.8, 7.9, $2.1 \mathrm{~Hz}, \mathrm{Ph}-\mathrm{H}$ ), 7.48-7.42 (m, 2H, Im-H), 7.39-7.27 (m, 2H, Ph-H), 7.20-7.04 (m, 2H, $\mathrm{Im}-\mathrm{H}), 4.54\left(\mathrm{~s}, 2 \mathrm{H}, \mathrm{S}-\mathrm{CH}_{2}\right)$; HRMS (FTMS + pESI) $\mathrm{m} / z$, calcd. for $\mathrm{C}_{14} \mathrm{H}_{10} \mathrm{~F}_{2} \mathrm{~N}_{2} \mathrm{~S}[\mathrm{M}+\mathrm{H}]^{+}: 277.0606$, found: 277.0590 .

\section{2-((2-Chlorobenzyl)thio)-1H-benzo[d]imidazole (6u)}

Purified by column chromatography eluting mixtures of hexanes and ethyl acetate (9:1 followed by $8: 2)$ to obtain the title compound as a light yellow solid in $35 \%$ yield; mp 157-160 ${ }^{\circ} \mathrm{C}$ (lit. $160-164{ }^{\circ} \mathrm{C}$ ); ${ }^{12} \mathrm{t}_{\mathrm{R}} 16.5 \mathrm{~min} ;{ }^{1} \mathrm{H}$ NMR (400 MHz, DMSO- $d_{6}$ ) $\delta 12.62$ (bs, $1 \mathrm{H}, \mathrm{NH}$ ), 7.62-7.43 (m, 4H, Ph-H), 7.33-7.21 (m, 2H, Im-H), 7.13 (dd, 2H, J 5.9, $3.0 \mathrm{~Hz}, \mathrm{Im}-\mathrm{H}), 4.65\left(\mathrm{~s}, 2 \mathrm{H}, \mathrm{S}-\mathrm{CH}_{2}\right)$; HRMS (FTMS + pESI) $\mathrm{m} / z$, calcd. for $\mathrm{C}_{14} \mathrm{H}_{11} \mathrm{ClN}_{2} \mathrm{~S}[\mathrm{M}+\mathrm{H}]^{+}:$275.0404, found: 275.0389 .

\section{2-((3-Chlorobenzyl)thio)-1H-benzo[d] imidazole (6v)}

Purified by column chromatography eluting mixtures of hexanes and ethyl acetate (9:1 followed by $8: 2)$ to obtain the title compound as a white solid in 59\% yield; mp 141-144 ${ }^{\circ} \mathrm{C}$ (lit. $145-147{ }^{\circ} \mathrm{C}$ ); ${ }^{12} \mathrm{t}_{\mathrm{R}} 16.6 \mathrm{~min} ;{ }^{1} \mathrm{H}$ NMR $\left(400 \mathrm{MHz}, \mathrm{DMSO}-d_{6}\right) \delta 12.60(\mathrm{bs}, 1 \mathrm{H}, \mathrm{NH}), 7.53(\mathrm{~d}, 1 \mathrm{H}$, $J 2.0 \mathrm{~Hz}, \mathrm{Ph}-\mathrm{H}$ ), 7.50-7.38 (m, 3H, Ph-H), 7.36-7.26 (m, $2 \mathrm{H}, \mathrm{Im}-\mathrm{H}$ ), 7.17-7.09 (m, 2H, Im-H), 4.56 (s, 2H, S-CH ${ }_{2}$; HRMS (FTMS + pESI) $\mathrm{m} / z$, calcd. for $\mathrm{C}_{14} \mathrm{H}_{11} \mathrm{ClN}_{2} \mathrm{~S}$ $[\mathrm{M}+\mathrm{H}]^{+}:$275.0404, found: 275.0388 .

\section{2-((4-Chlorobenzyl)thio)-1H-benzo[d]imidazole (6w)}

Purified by column chromatography eluting mixtures of hexanes and ethyl acetate (9:1 followed by $8: 2)$ to obtain the title compound as a white solid in $80 \%$ yield; mp 176-179 ${ }^{\circ} \mathrm{C}$ (lit. $180-181{ }^{\circ} \mathrm{C}$ ); ${ }^{12} \mathrm{t}_{\mathrm{R}} 16.6 \mathrm{~min} ;{ }^{1} \mathrm{H}$ NMR $\left(400 \mathrm{MHz}, \mathrm{DMSO}-d_{6}\right) \delta 12.59$ (bs, $\left.1 \mathrm{H}, \mathrm{NH}\right), 7.57-7.43$ (m, $3 \mathrm{H}, \mathrm{Ph}-\mathrm{H}$ ), 7.39-7.33 (m, 3H, $1 \mathrm{Ph}-\mathrm{H}$ and $2 \mathrm{Im}-\mathrm{H}$ ), 7.12 (dt, 2H, J 7.2, 3.6 Hz, Im-H), 4.56 (s, 2H, S-CH ${ }_{2}$ ); HRMS 
(FTMS + pESI) $m / z$, calcd. for $\mathrm{C}_{14} \mathrm{H}_{11} \mathrm{ClN}_{2} \mathrm{~S}[\mathrm{M}+\mathrm{H}]^{+}$: 275.0404, found: 275.0388 .

\section{2-((4-Bromobenzyl)thio)-1H-benzo[d]imidazole (6x)}

Purified by column chromatography eluting mixtures of hexanes and ethyl acetate (8:2 followed by 7:3) to obtain the title compound as a white solid in $76 \%$ yield; mp 195-198 ${ }^{\circ} \mathrm{C}$ (lit. 198-201 ${ }^{\circ} \mathrm{C}$ ) $;{ }^{12} \mathrm{t}_{\mathrm{R}} 16.8 \mathrm{~min} ;{ }^{1} \mathrm{H}$ NMR $\left(400 \mathrm{MHz}, \mathrm{DMSO}-d_{6}\right) \delta 12.55$ (bs, $\left.1 \mathrm{H}, \mathrm{NH}\right), 7.60-7.32$ $(\mathrm{m}, 6 \mathrm{H}, 4 \mathrm{Ph}-\mathrm{H}$ and $2 \mathrm{Im}-\mathrm{H}), 7.23-7.01(\mathrm{~m}, 2 \mathrm{H}, \mathrm{Im}-\mathrm{H})$, 4.54 (s, 2H, S- $\mathrm{CH}_{2}$ ); HRMS (FTMS + pESI) $\mathrm{m} / z$, calcd. for $\mathrm{C}_{14} \mathrm{H}_{11} \mathrm{BrN}_{2} \mathrm{~S}[\mathrm{M}+\mathrm{H}]^{+}: 318.9899$, found: 318.9880 .

\section{2-((3-(Trifluoromethyl)benzyl)thio)-1H-benzo[d]imidazole} (6y)

Purified by column chromatography eluting mixtures of hexanes and ethyl acetate (8:2 followed by $7: 3$ ) to obtain the title compound as a white solid in $80 \%$ yield; mp 146-149 ${ }^{\circ} \mathrm{C}$ (lit. $148-149.5^{\circ} \mathrm{C}$ ) $;{ }^{12} \mathrm{t}_{\mathrm{R}} 16.8 \mathrm{~min} ;{ }^{1} \mathrm{H}$ NMR $\left(400 \mathrm{MHz}, \mathrm{DMSO}-d_{6}\right) \delta 12.60(\mathrm{~s}, 1 \mathrm{H}, \mathrm{NH}), 7.85(\mathrm{~d}, 1 \mathrm{H}$, $J$ 2.0 Hz, Ph-H), 7.81-7.73 (m, 1H, Ph-H), 7.64-7.48 (m, 3H, $2 \mathrm{Ph}-\mathrm{H}$ and $1 \mathrm{Im}-\mathrm{H})$, 7.43-7.29 (m, 1H, Im-H), 7.19-7.07 (m, 2H, Im-H), 4.65 (s, 2H, S- $\left.\mathrm{CH}_{2}\right)$; HRMS (FTMS + pESI) $m / z$, calcd. for $\mathrm{C}_{15} \mathrm{H}_{11} \mathrm{~F}_{3} \mathrm{~N}_{2} \mathrm{~S}[\mathrm{M}+\mathrm{H}]^{+}$: 309.0668, found: 309.0657 .

\section{2-((3,5-Dinitrobenzyl)thio)-1H-benzo[d]imidazole (6z)}

Purified by column chromatography eluting mixtures of hexanes and ethyl acetate (8:2 followed by 7:3) to obtain the title compound as a yellow solid in $68 \%$ yield; mp 151-154 ${ }^{\circ} \mathrm{C}$ (lit. $155-158{ }^{\circ} \mathrm{C}$ ); ${ }^{12} \mathrm{t}_{\mathrm{R}} 16.5 \mathrm{~min} ;{ }^{1} \mathrm{H} \mathrm{NMR}$ $\left(400 \mathrm{MHz}, \mathrm{DMSO}-d_{6}\right) \delta 12.60$ (bs, $\left.1 \mathrm{H}, \mathrm{NH}\right), 8.83(\mathrm{~d}, 2 \mathrm{H}$, $J 2.1 \mathrm{~Hz}, \mathrm{Ph}-\mathrm{H}$ ), 8.66 (t, 1H, J 2.2 Hz, Ph-H), 7.43 (s, 2H, $\mathrm{Im}-\mathrm{H})$, 7.15-7.07 (m, 2H, Im-H), 4.79 (s, 2H, S- $\mathrm{CH}_{2}$ ); HRMS (FTMS + pESI) $\mathrm{m} / z$, calcd. for $\mathrm{C}_{14} \mathrm{H}_{10} \mathrm{~N}_{4} \mathrm{O}_{4} \mathrm{~S}$ $[\mathrm{M}+\mathrm{H}]^{+}$: 331.0496, found: 331.0482 .

\section{Susceptibility testing against $M$. tuberculosis}

The compounds were tested for their inhibitory potential against the M. tuberculosis H37Rv reference strain (ATCC 27294) by the resazurin reduction microplate assay (REMA), as thoroughly described previously. ${ }^{7,13,14}$ Stock solutions $\left(2 \mathrm{mg} \mathrm{mL}^{-1}\right)$ of the test compounds were made in neat DMSO and aliquots were stored at $-20^{\circ} \mathrm{C}$. The compounds were further diluted in $1 \mathrm{~mL}$ of Difco ${ }^{\mathrm{TM}}$ Middlebrook $7 \mathrm{H} 9$ broth (Becton Dickinson, BD, New Jersey, USA), supplemented with $10 \%(\mathrm{v} / \mathrm{v}) \mathrm{BBL}^{\mathrm{TM}}$ Middlebrook ADC enrichment (albumin, dextrose, and catalase; BD) and 5\% $(\mathrm{v} / \mathrm{v})$ DMSO. The maximum concentration tested for each compound ranged from 5 to $40 \mathrm{mg} \mathrm{mL}^{-1}$, due to differences in solubilities. The compounds were prepared as 10-point, 2 -fold serial dilutions directly in 96 -well plates. Three independent experiments were performed, and the MIC was considered to be the lowest compound concentration that prevented resazurin (Sigma-Aldrich, Saint Louis, USA) reduction, which is otherwise indicated by a color conversion from blue to pink. The MIC value reported for each compound was the most frequent value among the three assays or the highest value obtained, expressed in mass ( $\mu \mathrm{g}$ $\mathrm{mL}^{-1}$ ) or molar concentration $(\mu \mathrm{M})$.

\section{Susceptibility testing against multidrug-resistant M. tuberculosis strains}

Compounds $\mathbf{6 p}$ and $\mathbf{6 z}$ were further tested by REMA, as described above, for their inhibitory potential against three multidrug-resistant clinical isolates of M. tuberculosis. ${ }^{15}$ The clinical isolates (named PT2, PT12 and PT20) were obtained from patients in the Lisbon Health Region, Lisbon, Portugal. ${ }^{15}$ INH and RIF were used as control drugs to demonstrate the MDR phenotype of these isolates.

\section{Cytotoxicity investigation}

Cellular viability determination after incubation with the test compounds was performed using two different methods: the 3-(4,5-dimethylthiazol-2-yl)-2,5-diphenyltetrazolium bromide (MTT) method and neutral red uptake assay. ${ }^{16,17}$ First, Vero and HepG2cells were grown in Dulbecco's Modified Eagle Medium (DMEM) supplemented with 10\% inactivated fetal bovine serum, $1 \%$ antibiotic (gentamicin) and $0.01 \%$ antifungal (amphotericin B). Cells were seeded at $4 \times 10^{3}(\mathrm{HepG} 2)$ or $2 \times 10^{3}$ cells per well (Vero) in a 96-well microtiter plate, and incubated for $24 \mathrm{~h}$. Test compounds were diluted in three different concentrations $(1,5$ and $20 \mathrm{mM})$ using $2 \%$ DMSO, and were incubated with the cell lines for $72 \mathrm{~h}$ at $37^{\circ} \mathrm{C}$ under $5 \% \mathrm{CO}_{2} \cdot{ }^{18}$ For the MTT assay, the cultures were incubated with MTT reagent $\left(5 \mathrm{mg} \mathrm{mL}^{-1}\right)$ for $4 \mathrm{~h}$. The absorbance was measured using excitation and emission wavelengths of 570 and $655 \mathrm{~nm}$, respectively (SpectraMax M2e, Molecular Devices, San Jose, USA). The precipitated purple formazan crystals were directly proportional to the number of live cells with active mitochondria. For the neutral red assay, after $72 \mathrm{~h}$ of incubation with the compounds, the cells were washed with PBS before the addition of $200 \mathrm{~mL}$ of neutral red dye solution ( $25 \mathrm{mg} \mathrm{mL}^{-1}$, Sigma, Saint Louis, USA) prepared in serum-free medium. The plate was incubated for an additional $3 \mathrm{~h}$ at $37{ }^{\circ} \mathrm{C}$ under $5 \% \mathrm{CO}_{2}$. After incubation, cells were washed with PBS, followed by incubation with 
$100 \mathrm{~mL}$ of a desorb solution $\left(\mathrm{CH}_{3} \mathrm{COOH} / \mathrm{EtOH} / \mathrm{H}_{2} \mathrm{O}\right.$, 1:50:49) for $30 \mathrm{~min}$, with gentle shaking to extract neutral red dye from the viable cells. The absorbance was measured at $562 \mathrm{~nm}$ using a microtiter plate reader. The percentage of cell viability for the treated groups was reported by considering the control wells ( $2 \%$ DMSO) as $100 \%$ of cell viability: cell viability $(\%)=($ absorbance of treated wells/ absorbance of control wells) $\times 100$. Statistical analysis was performed using one-way analysis of variance using GraphPad Prism 5.0 software. ${ }^{19}$

\section{Solubility assay and plasma stability}

The solubility tests were performed according to a previously published protocol, ${ }^{20}$ with slight modifications. Accordingly, $1 \mathrm{~mL}$ of a prepared solution $(1 \times \mathrm{PBS}, \mathrm{pH}$ 7.4 or $0.1 \mathrm{~mol} \mathrm{~L}^{-1} \mathrm{HCl}, \mathrm{pH} 1.0$ ) was added to $1 \mathrm{mg}$ of compound (in triplicate). The final solutions were vortexed $(1 \mathrm{~min})$ and the resulting suspensions were shaken for $4 \mathrm{~h}$ at $25^{\circ} \mathrm{C}$. Then, the solutions were centrifuged $(13000 \mathrm{rpm}$ for $15 \mathrm{~min}$ at $25^{\circ} \mathrm{C}$ ) obtaining a pellet and the remaining solutions were quantified by liquid chromatography (as per the conditions described in the Experimental section) using single-point calibration of a known concentration of the compounds in DMSO.

The plasma stability was also conducted according to the literature. ${ }^{21}$ Compounds $\mathbf{6 p}$ and $\mathbf{6 z}$ were dissolved separately in DMSO to a concentration of $800 \mu \mathrm{M}$. The stock samples were prepared in triplicate. Subsequently, commercially-obtained mice plasma (Equitech-Bio, Inc, Kerrville, USA) was diluted with PBS $1 \times(\mathrm{pH} 7.4)$ to obtain a stock solution (1:1). Afterwards, $5 \mu \mathrm{L}$ of each stock sample were diluted with $195 \mu \mathrm{L}$ of stock solution, obtaining an appropriate assay condition $(20 \mu \mathrm{M}$ of sample concentration, $50 \%$ of plasma concentration in buffer, and $2.5 \%$ of DMSO) ${ }^{21}$ Afterward, the samples were vortexed (1 min) and incubated at $37{ }^{\circ} \mathrm{C}$ in a shaker for $3 \mathrm{~h}$. At the end of the incubation, acetonitrile $(600 \mu \mathrm{L})$ was added, and the samples were centrifuged at $13000 \mathrm{rpm}$ for $15 \mathrm{~min}$ $\left(4{ }^{\circ} \mathrm{C}\right)$. The supernatants obtained were analyzed using liquid chromatography.

\section{Results and Discussion}

The synthesis of the designed compounds was performed in one single and easy-to-perform synthetic step. The desired molecules were obtained using a secondorder nucleophilic substitution reaction $\left(\mathrm{S}_{\mathrm{N}} 2\right)$ between 2-mercapto-5-methoxy-1H-benzo[ $d]$ imidazole $4 \mathbf{a}$ and different benzyl halides (5) (Scheme 1). The reaction was performed in the presence of potassium carbonate as a base and DMF as the solvent, at room temperature for 2-6 h (Scheme 1). The products 6 were isolated with yields varying from 22 to $95 \%$ and purities over $90 \%$, as determined by HPLC analysis. Spectroscopic (Supplementary Information section) and spectrometric data were found to be in total agreement with the proposed structures.
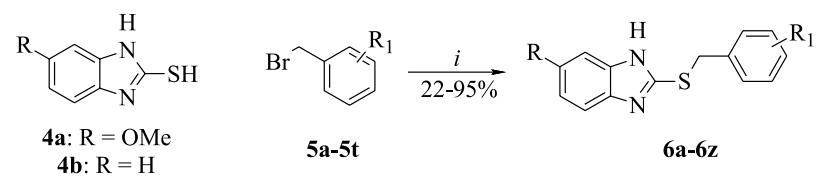

Scheme 1. Reagents and conditions: $i=\mathrm{K}_{2} \mathrm{CO}_{3}$, DMF, $25^{\circ} \mathrm{C}, 2-6 \mathrm{~h}$.

It is noteworthy that proposed structural modifications were aimed at the creation of an electron density gradient of the substituents in a preliminary SAR study.

Afterwards, all synthesized $1 H$-benzo $[d]$ imidazoles 6 were tested in whole-cell assays against $M$. tuberculosis H37Rv, using the first-line drug INH as a reference in accordance with previously-described protocols. ${ }^{13,14}$ In general, the screening revealed that most compounds evaluated showed moderate activity or were inactive at the highest doses tested. In contrast, 3,5-dinitro compounds $\mathbf{6 p}$ and $\mathbf{6 z}$ exhibited good activity, with MIC values similar to the first-line anti-TB drug INH (Table 1). From proposed substituents, one can conclude that the non-substituted compound 6a did not show antimycobacterial activity at the highest concentration tested. Positioning fluorine atoms at the 2-, 3- or 4-position of the benzene ring (6b-6d) did not produce structures capable of inhibiting the growth of mycobacteria under the evaluated conditions. Interestingly, the presence of two fluorine atoms attached at the 3,4-positions of the benzene ring resulted in a structure with modest activity against Mtb. The difluorinated compound 6e was able to inhibit mycobacterial growth, with an MIC value of $130.6 \mu \mathrm{M}$. The presence of chlorine atoms at the 2-, 3- or 4-position in compounds $6 \mathbf{6}-\mathbf{6 h}$ also produced molecules with modest and equipotent activities, with MIC values of $131.2 \mu \mathrm{M}$. Compared to monofluorinated compounds 6b-6d, chlorinated molecules 6f-6h have higher lipophilicity (Table 1), which may be related to the higher antimycobacterial activity observed for these structures. When two chlorine atoms were positioned at the 3,4-positions of the benzene ring (6i), the molecule was inactive against $\mathrm{Mtb}$ at the highest concentrations evaluated. The bioisosteric exchange between chlorine and bromine was well-tolerated, as compound $\mathbf{6 j}$ showed an MIC value of $114.5 \mu \mathrm{M}$. Likewise, the 3-trifluoromethyl group attached at position 3 provided the structure $\mathbf{6 k}$, which exhibited an MIC value of $118.2 \mu \mathrm{M}$. Positioning 
the trifluoromethyl group at the 4-position in $\mathbf{6 1}$ generated an inactive compound when tested at $20 \mu \mathrm{M}$ concentration. Continuing the evaluation of electron-withdrawing chemical groups, the presence of the nitro group at the 2-, 3- or 4-position of the benzenic ring $(\mathbf{6 m - 6 0})$ produced inactive structures when tested at the highest concentrations permitted due to the molecules' solubilities. Indeed, $1 H$-benzo[ $d]$ imidazoles $\mathbf{6 m - 6 o}$ presented MIC $>10 \mu \mathrm{M}$. In contrast, the dinitro-substituted compound $\mathbf{6 p}$ exhibited a good capacity to inhibit the growth of $M$. tuberculosis $\mathrm{H} 37 \mathrm{Rv}$ in vitro. The structure showed an MIC value of $6.9 \mu \mathrm{M}$, only 3 -fold less potent when compared to the firstline drug INH. The use of electron-donating substituents in compounds $\mathbf{6 q}$ and $\mathbf{6 r}$ did not furnish active structures against Mtb. Furthermore, the sulfonomethyl-substituted compound 6s also did not show inhibitory activity on the bacillus growth at the highest concentration evaluated.

In the second round of evaluation of the activity of $1 H$-benzo[d]imidazole derivatives, the contribution of the methoxy group attached at the 5-position of the heterocyclic ring was evaluated. Compounds $6 \mathbf{u}-\mathbf{6 z}$ were obtained from the $S$-alkylation reaction of 2-mercapto$1 H$-benzo[ $[d]$ imidazole $\mathbf{4 b}$, using the substituents of the most effective 5-methoxy-based structures. In general, the absence of the methoxy group reduced the growth inhibition effectiveness against the M. tuberculosis H37Rv strain. Unlike $1 H$-benzo[ $[d$ imidazoles $\mathbf{6 v}$ and $\mathbf{6 z}$, the other compounds were inactive at the highest concentrations tested. While the 3-chloro-substituted compound showed an MIC value of $145.6 \mu \mathrm{M}$, the molecule containing the 3,5-dinitro group showed inhibition of mycobacterial growth with an MIC of $3.8 \mu \mathrm{M}$. The activity shown by compound $6 \mathbf{z}$ was similar to INH when tested under the same experimental conditions.

It is important to mention that $1 H$-benzo $[d]$ imidazoles $6 \mathbf{u}-\mathbf{6 z}$ have previously been evaluated against M. tuberculosis $331 / 88$ strain. ${ }^{12}$ Despite the different experimental conditions and differences between Mtb strains, the MIC values observed were similar. However, to the best of our knowledge, the activity of compound $\mathbf{6 z}$ against multidrug-resistant strains has not been described. Therefore, the two most active $1 H$-benzo $[d]$ imidazoles $(\mathbf{6 p}$

Table 1. Yields of 2-(benzylthio)- $1 H$-benzo[d]imidazoles $\mathbf{6 a - 6 z}, \mathrm{Clog} \mathrm{P}$ values, and in vitro activities against $M$. tuberculosis $\mathrm{H} 37 \mathrm{Rv}$ strain

\begin{tabular}{|c|c|c|c|c|c|c|}
\hline Compound & $\mathrm{R}$ & $\mathrm{R}^{1}$ & Yield $^{\mathrm{a}} / \%$ & $\mathrm{C} \log \mathrm{P}^{\mathrm{b}}$ & $\begin{array}{c}\mathrm{MIC}(\mathrm{H} 37 \mathrm{Rv})^{\mathrm{c}} / \\
\left(\mu \mathrm{g} \mathrm{mL} \mathrm{m}^{-1}\right)\end{array}$ & $\begin{array}{c}\mathrm{MIC}(\mathrm{H} 37 \mathrm{Rv})^{\mathrm{c}} / \\
\mu \mathrm{M}\end{array}$ \\
\hline $6 \mathbf{6 a}$ & $\mathrm{OMe}$ & $\mathrm{H}$ & 67 & 4.58 & $>40$ & 148.0 \\
\hline $6 \mathbf{b}$ & $\mathrm{OMe}$ & $2-\mathrm{F}$ & 80 & 4.72 & $>40$ & $>138.7$ \\
\hline $6 c$ & $\mathrm{OMe}$ & $3-\mathrm{F}$ & 66 & 4.72 & $>40$ & $>138.7$ \\
\hline $6 d$ & $\mathrm{OMe}$ & 4-F & 70 & 4.72 & $>40$ & $>138.7$ \\
\hline $6 e$ & $\mathrm{OMe}$ & $3,4-(F)_{2}$ & 70 & 4.79 & 40 & 130.6 \\
\hline 6f & $\mathrm{OMe}$ & 2-Cl & 90 & 5.29 & 40 & 131.2 \\
\hline $6 \mathrm{~g}$ & $\mathrm{OMe}$ & $3-\mathrm{Cl}$ & 74 & 5.29 & 40 & 131.2 \\
\hline $6 h$ & $\mathrm{OMe}$ & 4-Cl & 95 & 5.29 & 40 & 131.2 \\
\hline $6 \mathbf{i}$ & OMe & $3,4-(\mathrm{Cl})_{2}$ & 72 & 5.88 & $>40$ & $>117.9$ \\
\hline $6 \mathbf{j}$ & $\mathrm{OMe}$ & 4-Br & 68 & 5.44 & 40 & 114.5 \\
\hline $6 \mathbf{k}$ & $\mathrm{OMe}$ & $3-\mathrm{CF}_{3}$ & 78 & 5.46 & 40 & 118.2 \\
\hline 61 & $\mathrm{OMe}$ & $4-\mathrm{CF}_{3}$ & 76 & 5.46 & $>20$ & $>59.1$ \\
\hline $6 m$ & $\mathrm{OMe}$ & $2-\mathrm{NO}_{2}$ & 82 & 4.24 & $>10$ & $>31.7$ \\
\hline $6 n^{d}$ & $\mathrm{OMe}$ & $3-\mathrm{NO}_{2}$ & 66 & 4.32 & $>40$ & $>126.8$ \\
\hline 60 & $\mathrm{OMe}$ & 4- $\mathrm{NO}_{2}$ & 86 & 4.32 & $>10$ & $>31.7$ \\
\hline $6 p$ & $\mathrm{OMe}$ & $3,5-\left(\mathrm{NO}_{2}\right)_{2}$ & 85 & 4.06 & 2.50 & 6.9 \\
\hline $6 q$ & OMe & 4-iPr & 81 & 6.00 & $>5$ & $>16.0$ \\
\hline $6 \mathbf{r}$ & $\mathrm{OMe}$ & 4- $t \mathrm{Bu}$ & 78 & 6.04 & $>5$ & $>15.3$ \\
\hline $6 s$ & OMe & $4-\mathrm{SO}_{2} \mathrm{Me}$ & 83 & 2.94 & $>20$ & $>57.4$ \\
\hline $6 t$ & $\mathrm{H}$ & $3,4-(\mathrm{F})_{2}$ & 22 & 4.49 & $>40$ & $>144.8$ \\
\hline $6 u$ & $\mathrm{H}$ & $2-\mathrm{Cl}$ & 35 & 4.98 & $>10$ & $>36.4$ \\
\hline $6 v$ & $\mathrm{H}$ & $3-\mathrm{Cl}$ & 59 & 4.98 & 40 & 145.6 \\
\hline $6 w$ & $\mathrm{H}$ & $4-\mathrm{Cl}$ & 80 & 4.98 & $>10$ & $>36.4$ \\
\hline $6 x$ & $\mathrm{H}$ & $4-\mathrm{Br}$ & 76 & 5.14 & $>5$ & $>15.7$ \\
\hline $6 y$ & $\mathrm{H}$ & $3-\mathrm{CF}_{3}$ & 80 & 5.16 & $>10$ & $>32.4$ \\
\hline $6 z$ & $\mathrm{H}$ & $3,5-\left(\mathrm{NO}_{2}\right)_{2}$ & 68 & 3.76 & 1.25 & 3.8 \\
\hline INH & - & - & - & -0.67 & 0.3 & 2.3 \\
\hline
\end{tabular}

Isolated yield; ${ }^{b} \operatorname{logarithm}$ of partition coefficient calculated by ChemBioDraw Ultra, version 13.0.0.3015; ${ }^{22} \mathrm{c}$ minimal inhibitory concentration; ${ }^{\mathrm{d}}$ reaction performed at $40^{\circ} \mathrm{C}$ for $4 \mathrm{~h}$. INH: isoniazid. 
Table 2. Selected 2-(benzylthio)-1H-benzo[d]imidazoles, ClogP values, in vitro activities against $M$. tuberculosis H37Rv and multidrug-resistant M. tuberculosis strains, and evaluation of the viability of Vero and HepG2 cells

\begin{tabular}{|c|c|c|c|c|c|c|c|c|c|c|c|c|c|}
\hline Compound & $\mathrm{Clog} \mathrm{P}^{\mathrm{a}}$ & $\begin{array}{c}\text { MIC } \\
\text { H37Rv / } \\
\left(\mu \mathrm{g} \mathrm{mL} L^{-1}\right)\end{array}$ & $\begin{array}{c}\text { MIC } \\
\text { H37Rv / } \\
\mu \mathrm{M}\end{array}$ & $\begin{array}{l}\mathrm{MIC} \mathrm{PT2}^{\mathrm{b}} / \\
\left(\mu \mathrm{g} \mathrm{mL} L^{-1}\right)\end{array}$ & $\begin{array}{l}\text { MIC } \\
\text { PT2 }^{\mathrm{b}} / \\
\mu \mathrm{M}\end{array}$ & $\begin{array}{c}\text { MIC } \\
\text { PT1 }^{\mathrm{b}} / \\
\left(\mu \mathrm{g} \mathrm{mL} L^{-1}\right)\end{array}$ & $\begin{array}{l}\text { MIC } \\
\text { PT12 / } \\
\mu \mathrm{M}\end{array}$ & $\begin{array}{c}\text { MIC } \\
{\mathrm{PT} 20^{\mathrm{b}} /}_{\left(\mu \mathrm{g} \mathrm{mL} L^{-1}\right)}\end{array}$ & $\begin{array}{c}\text { MIC } \\
\text { PT20 / } \\
\mu \mathrm{M}\end{array}$ & $\begin{array}{c}\mathrm{CC}_{50} \text { Vero }^{\mathrm{c}} / \\
\left(\mu \mathrm{g} \mathrm{mL} \mathrm{m}^{-1}\right)\end{array}$ & $\begin{array}{c}\mathrm{CC}_{50} \text { Vero }^{\mathrm{c}} / \\
\mu \mathrm{M}\end{array}$ & $\begin{array}{c}\mathrm{CC}_{50} \\
\mathrm{HepG2}^{\mathrm{c}} / \\
\left(\mu \mathrm{g} \mathrm{mL}^{-1}\right)\end{array}$ & $\begin{array}{c}\mathrm{CC}_{50} \\
\mathrm{HepG}^{\mathrm{c}} / \\
\mu \mathrm{M}\end{array}$ \\
\hline $6 p$ & 4.06 & 2.5 & 6.9 & 2.5 & 6.9 & 2.5 & 6.9 & 10 & 27.6 & $>7.2$ & $>20$ & $>7.2$ & $>20$ \\
\hline $6 z$ & 3.76 & 1.25 & 3.8 & 2.5 & 7.6 & 5 & 15.2 & 10 & 30.4 & $>6.6$ & $>20$ & $>6.6$ & $>20$ \\
\hline INH & -0.67 & 0.3 & 2.3 & 40 & 291.7 & 20 & 145.8 & 40 & 291.7 & - & - & - & - \\
\hline RIF & 3.71 & 0.08 & 0.1 & $>40$ & $>48.6$ & $>40$ & $>48.6$ & $>40$ & $>48.6$ & - & - & - & - \\
\hline
\end{tabular}

${ }^{2}$ Logarithm of partition coefficient calculated by ChemBioDraw Ultra, version 13.0.0.3015;22 bultidrug-resistant clinical isolates of M. tuberculosis; ${ }^{\mathrm{c}}$ the toxicity and selectivity of the compounds was studied on $\mathrm{HepG} 2$ and Vero cells. The $50 \%$ cytotoxic concentration $\left(\mathrm{CC}_{50}\right)$ determined by MTT and neutral red assays. Vero are kidney epithelial cells from African green monkey (Cercopithecus aethiops). HepG2 are lineage of cells isolated from human hepatocyte carcinoma. INH: isoniazid; RIF: rifampicin.

and $\mathbf{6 z}$ ) were selected for both inhibitory activity of three multidrug-resistant M. tuberculosis strains (PT2, PT12, and PT20) and for viability studies, using Vero and HepG2 cells (Table 2). The multidrug-resistant strains PT2, PT12, and PT20 have been described as resistant to drugs such as INH, RIF, streptomycin, ethionamide, and rifabutine. ${ }^{15}$ Additionally, PT12 and PT20 are also resistant to drugs such as PZA and ETH, and PT12 presents additional resistance to amikacin and capreomycin. ${ }^{15}$ Considering the PT2 strain, both molecules maintained similar MIC results, demonstrating that $\mathbf{6 p}$ and $\mathbf{6 z}$ possibly do not share the same drug resistance mechanism of INH, RIF, streptomycin, ethionamide, and rifabutine. Unlike compound $\mathbf{6 p}$, the MIC value presented by $1 H$-benzo[ $[d$ imidazole $\mathbf{6 z}$ was 4-fold lower against the PT12 strain compared to that observed for the M. tuberculosis H37Rv strain (Table 2). This finding infers that structure $\mathbf{6 z}$ may share resistance mechanisms with one or more drugs between PZA, ETH, amikacin, and capreomycin. Interestingly, the PT20 strain showed resistance to inhibitory action promoted by compounds $6 \mathbf{p}$ and $\mathbf{6 z}$. These molecules were 4 - and 8 -fold less active against PT20, respectively, when compared to MIC values against the M. tuberculosis $\mathrm{H} 37 \mathrm{Rv}$ strain. These data suggest that $1 H$-benzo[ $d]$ imidazole $\mathbf{6 p}$ may share the resistance mechanism with the first-line drugs PZA and/or ETH. It is noteworthy that both molecules $(\mathbf{6 p}$ and 6z) were active against all multidrug-resistant strains tested, with MIC values lower than those of the first-line drugs INH and RIF (Table 2). Finally, the presence of the methoxy group seems to increase the spectrum of action of compound $\mathbf{6 p}$, considering the assayed strains. However, more studies are needed to clarify the resistance mechanism, action mechanism and spectrum of activity of synthesized $1 \mathrm{H}$-benzo[d]imidazoles.

In order to assess selectivity, the basic principle of pharmacology, and the cytotoxicity of nitrated derivatives $\mathbf{6 p}$ and $\mathbf{6 z}$, the viability of the Vero and HepG2 cells in the presence of these molecules was determined.
Although compounds containing nitro groups attached to aromatic systems have been associated with toxicity per se, exposing the HepG2 and Vero cell lineages to $\mathbf{6 p}$ and $\mathbf{6 z}$ for $72 \mathrm{~h}^{18}$ did not significantly affect the cell viability (Table 2 ). Cellular viability was determined after incubation with the test compounds at 1, 5 and $20 \mu \mathrm{M}$, using the MTT method and neutral red uptake assay. While MTT determines mitochondrial activity, ${ }^{16}$ neutral red assesses the lysosomal viability of the cells. ${ }^{17}$ The results suggest a possible low toxicity of the compounds to mammalian cells, and a likely high degree of selectivity for Mtb.

Solubility and stability have been described as important properties in early drug discovery. ${ }^{23}$ Thus, $1 H$-benzo $[d]$ imidazoles $\mathbf{6 p}$ and $\mathbf{6 z}$ were evaluated for their solubilities in PBS (pH 7.4) and $0.1 \mathrm{~mol} \mathrm{~L}^{-1} \mathrm{HCl}$ (pH 1.0) (Table 3). The solubility of these compounds was markedly higher at $\mathrm{pH} 1.0$ than in aqueous solution at $\mathrm{pH}$ 7.4. The compounds $\mathbf{6 p}$ and $\mathbf{6 z}$ exhibited solubilities of $26.9 \pm 0.6 \mu \mathrm{M}$ and $11.2 \pm 1.2 \mu \mathrm{M}$ at $\mathrm{pH} 7.4$, respectively. The solubility was improved at $\mathrm{pH} 1.0$, with $324 \pm 39 \mu \mathrm{M}$ for compound $6 \mathbf{p}$ and $339 \pm 6 \mu \mathrm{M}$ for its analogue $\mathbf{6 p}$. These observed values are higher than $100 \mu \mathrm{M}$, which has been described as a cutoff in early drug discovery programs. ${ }^{23} \mathrm{In}$ addition, the plasma stability of 3,5-dinitro compounds $\mathbf{6 p}$ and $\mathbf{6 z}$ was also determined. After incubation for $3 \mathrm{~h}$ at $37{ }^{\circ} \mathrm{C}$, the evaluated molecules showed higher than $95 \%$ of their initial concentrations (Table 3). This stability is consistent with the assessment of activity of these structures in TB animal models.

Table 3. Solubility and plasma stability of 2-(benzylthio)- $1 H$-benzo $[d]$ imidazoles $\mathbf{6 p}$ and $\mathbf{6 z}$

\begin{tabular}{lccc}
\hline \multirow{2}{*}{ Compound } & \multicolumn{2}{c}{ Solubility } & $\begin{array}{c}\text { Plasma } \\
n_{\text {stability } / \%}\end{array}$ \\
\cline { 2 - 3 } $\mathbf{6 p}$ & $\mathrm{PBS}^{\mathrm{a}} / \mu \mathrm{M}$ & $0.1 \mathrm{~mol} \mathrm{~L}^{-1} \mathrm{HCl} / \mu \mathrm{M}$ & 95.7 \\
$\mathbf{6 z}$ & $26.9 \pm 0.6$ & $324 \pm 39$ & 96.7 \\
\hline
\end{tabular}

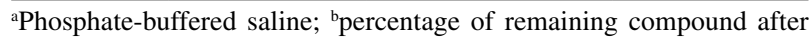
$3 \mathrm{~h}$ at $37^{\circ} \mathrm{C}$. 


\section{Conclusions}

In summary, herein the synthesis of new series of 2-(benzylthio)-1H-benzo[d]imidazoles and their in vitro antitubercular activities have been shown. The compounds were obtained in reasonable yields and high purity, through a simple and easy-to-perform, onestep synthetic approach, from accessible reactants and reagents. In addition, some compounds showed activity against wild-type Mtb, and the leading compounds showed activity against multidrug-resistant Mtb strains with no apparent cytotoxicity to mammalian cells. Finally, leading compounds have shown good aqueous solubility and high plasma stability. These results suggest that this class of compounds may provide candidates for the future development of new therapeutic alternatives for the treatment of tuberculosis.

\section{Supplementary Information}

Supplementary information $\left({ }^{1} \mathrm{H}\right.$ NMR spectra for all compounds) is available free of charge at http://jbcs.sbq.org.br as PDF file.

\section{Acknowledgments}

This work was supported by CNPq/FAPERGS/CAPES/ BNDES, Brazil (grant numbers: 421703-2017-2/17-1265-8/ 14.2.0914.1) to C. V. B., L. A. B., and P. M. In addition, this study was financed in part by the Coordenação de Aperfeiçoamento de Pessoal de Nível Superior, Brazil (CAPES), finance code 001. C. V. B., L. A. B., and P. M. are Research Career Awardees of the National Research Council of Brazil (CNPq). The fellowships from CNPq (R. S. R., E.C.W., B. L. A., A. S. D., and N. S.) and CAPES (M. D. S.) are also acknowledged. Finally, we are grateful to Dr Miguel Viveiros from the Universidade Nova de Lisboa (Lisbon, Portugal) for providing the clinical isolates of $M$. tuberculosis used in this study.

\section{Author Contributions}

RSR was responsible for investigation, conceptualization, writing original draft; ECW for investigation; BLA for investigation; MDS for investigation; ASD for investigation; NS for investigation; CVB for conceptualization, project administration; $\mathrm{LAB}$ for conceptualization, project administration; PM for conceptualization, project administration; writing-review and editing.

\section{References}

1. https://www.who.int/publications/i/item/9789240013131, accessed in March 2021.

2. Pai, M.; Behr, M. A.; Dowdy, D.; Dheda, K.; Divangahi, M.; Boehme, C. C.; Ginsberg, A.; Swaminathan, S.; Spigelman, M.; Getahun, H.; Menzies, D.; Raviglione, M.; Nat. Rev. Dis. Primers 2016, 2, 16076

3. Koul, A.; Arnoult, E.; Lounis, N.; Guillemont, J.; Andries, K.; Nature 2011, 469, 483.

4. Tiberi, S.; Buchanan, R.; Caminero, J. A.; Centis, R.; Arbex, M. A.; Salazar-Lezama, M. A.; Potter, J.; Migliori, G. B.; Presse Med. 2017, 46, e41.

5. Bloemberg, G. V.; Keller, P. M.; Stucki, D.; Trauner, A.; Borrell, S.; Latshang, T.; Coscolla, M.; Rothe, T.; Hömke, R.; Ritter, C.; Feldmann, J.; Schulthess, B.; Gagneux, S.; Böttger, E. C.; N. Engl. J. Med. 2015, 373, 1986.

6. Pissinate, K.; Villela, A. D.; Rodrigues-Junior, V.; Giacobbo, B. C.; Grams, E. S.; Abbadi, B. L.; Trindade, R. V.; Nery, L. R.; Bonan, C. D.; Back, D. F.; Campos, M. M.; Basso, L. A.; Santos, D. S.; Machado, P.; ACS Med. Chem. Lett. 2016, 7, 235.

7. Giacobbo, B. C.; Pissinate, K.; Rodrigues-Junior, V.; Villela, A. D.; Grams, E. S.; Abbadi, B. L.; Subtil, F. T.; Sperotto, N.; Trindade, R. V.; Back, D. F.; Campos, M. M.; Basso, L. A.; Machado, P.; Santos, D. S.; Eur. J. Med. Chem. 2017, 126, 491.

8. Borsoi, A. F.; Paz, J. D.; Abbadi, B. L.; Macchi, F. S.; Sperotto, N.; Pissinate, K.; Rambo, R. S.; Ramos, A. S.; Machado, D.; Viveiros, M.; Bizarro, C. V.; Basso, L. A.; Machado, P.; Eur. J. Med. Chem. 2020, 192, 112179.

9. Macchi, F. S.; Pissinate, K.; Villela, A. D.; Abbadi, B. L.; Rodrigues-Junior, V.; Nabinger, D. D.; Altenhofen, S.; Sperotto, N.; Dadda, A. S.; Subtil, F. T.; Freitas, T. F.; Rauber, A. P. E.; Borsoi, A. F.; Bonan, C. D.; Bizarro, C. V.; Basso, L. A.; Santos, D. S.; Machado, P.; Eur. J. Med. Chem. 2018, 155, 155.

10. Rybniker, J.; Vocat, A.; Sala, C.; Busso, P.; Pojer, F.; Benjak, A.; Cole, S. T.; Nat. Commun. 2015, 6, 7659.

11. Foti, R. S.; Rock, D. A.; Han, X.; Flowers II, R. A.; Wienkers, L. C.; Wahlstrom, J. L.; J. Med. Chem. 2012, 55, 1205.

12. Klimešová, V.; Koči, J.; Pour, M.; Stachel, J.; Waisser, K.; Kaustová, J.; Eur. J. Med. Chem. 2002, 37, 409.

13. Ballell, L.; Bates, R. H.; Young, R. J.; Alvarez-Gomez, D.; Alvarez-Ruiz, E.; Barroso, V.; Blanco, D.; Crespo, B.; Escribano, J.; González, R.; Lozano, S.; Huss, S.; SantosVillarejo, A.; Martín-Plaza, J. J.; Mendoza, A.; Rebollo-Lopez, M. J.; Remuiñan-Blanco, M.; Lavandera, J. L.; Pérez-Herran, E.; Gamo-Benito, F. J.; García-Bustos, J. F.; Barros, D.; Castro, J. P.; Cammack, N.; ChemMedChem 2013, 8, 313.

14. Palomino, J.; Martin, A.; Camacho, M.; Guerra, H.; Swings, J.; Portaels, F.; Antimicrob. Agents Chemother. 2002, 46, 2720.

15. Perdigão, J.; Silva, H.; Machado, D.; Macedo, R.; Maltez, F.; Silva, C.; Jordao, L.; Couto, I.; Mallard, K.; Coll, F.; 
Hill-Cawthorne, G. A.; McNerney, R.; Pain, A.; Clark, T. G.; Viveiros, M.; Portugal, I.; BMC Genomics 2014, 15, 991.

16. Stockert, J. C.; Horobin, R. W.; Colombo, L. L.; Blázquez-Castro, A.; Acta Histochem. 2018, 120, 159.

17. Repetto, G.; del Peso, A.; Zurita, J. L.; Nat. Protoc. 2008, 3 , 1125.

18. Komissarova, E. V.; Saha, S. K.; Rossman, T. G.; Toxicol. Appl. Pharmacol. 2005, 202, 99.

19. GraphPad Prism, version 5.00; GraphPad Software, Inc., USA, 2007.

20. Moure, A. L.; Narula, G.; Sorrentino, F.; Bojang, A.; Tsui, C. K. M.; Emani, C. S.; Porras-De Francisco, E.; Díaz, B.; Rebollo-López, M. J.; Torres-Gómez, P. A.; López-Román, E.
M.; Camino, I.; Castro, P. C.; López, L. G.; Ortega, F.; Ballell, L.; Barros-Aguirre, D.; Blanco, M. R.; Av-Gay, Y.; J. Med. Chem. 2020, 4732.

21. Di, L.; Kerns, E. H.; Hong, Y.; Chen, H.; Int. J. Pharm. 2005, 110.

22. ChemBioDraw Ultra, version 13.0.0.3015; CambridgeSoftPerkinElmer, Waltham, USA, 2012.

23. Hughes, J. P.; Rees, S.; Kalindjian, S. B.; Philpott, K. L.; Br. J. Pharmacol. 2011, 162, 1239.

Submitted: January 21, 2021 Published online: March 30, 2021 